\title{
miR-26b is downregulated in human tongue squamous cell carcinoma and regulates cell proliferation and metastasis through a COX-2-dependent mechanism
}

\author{
JING CAO $^{1}$, TAO GUO ${ }^{2}$, QINGSHAN DONG ${ }^{3}$, JIANQIANG ZHANG $^{1}$ and YANFENG LI ${ }^{1}$ \\ ${ }^{1}$ Department of Stomatology, The First Affiliated Hospital of the PLA General Hospital, Beijing; ${ }^{2}$ Department of Stomatology, \\ The Fifth Affiliated Hospital, Xinjiang Medical University, Urumqi; ${ }^{3}$ Department of Stomatology, Wuhan General Hospital \\ of Guangzhou Command, People's Liberation Army, Wuhan, P.R. China
}

Received September 18, 2014; Accepted November 11, 2014

DOI: $10.3892 /$ or.2014.3648

\begin{abstract}
MicroRNAs (miRNAs) are important gene regulators that play a profound role in tumorigenesis. Previous studies have revealed that miR-26b is downregulated in a wide range of malignant tumors and plays an important role in the regulation of carcinogenesis and tumor progression. In the present study, we revealed that miR-26b expression was decreased in human tongue squamous cell carcinoma and was associated with clinical stage, lymph node metastasis and survival prognosis. Ectopic expression of miR-26b suppressed the proliferation and metastasis of human tongue squamous cell carcinoma cells. Using a luciferase reporter assay, combined with western blot analysis results, we identified PTGS2 (prostaglandinendoperoxide synthase-2, encoding $\mathrm{COX}-2$ ) as the functional target of miR-26b. Specific inhibition of COX-2 activity by nimesulide further confirmed that miR-26b was able to regulate the cell proliferation and metastasis of the human tongue squamous cell carcinoma cells through a COX-2-dependent mechanism. Taken together, these results suggest that miR-26b serves as a tumor suppressor by targeting COX-2 and calls for the use of miR-26b as a potential therapeutic tool for human tongue squamous cell carcinoma, where COX-2 is often hyperactivated.
\end{abstract}

\section{Introduction}

Oral squamous cell carcinoma (OSCC) represents 1-3\% of all human malignancies, among which, tongue squamous cell carcinoma represents $25-50 \%$ of all cases of OSCC (1-3). Tongue squamous cell carcinoma is characterized by its high

Correspondence to: Professor Yanfeng Li, Department of Stomatology, First Affiliated Hospital of The PLA General Hospital, Beijing, P.R. China

E-mail: liyanfeng304@163.com

Key words: miR-26b, COX-2, proliferation, tongue squamous cell carcinoma, metastasis rate of proliferation and nodal metastasis. Although it is visibly located in the oral cavity, $50 \%$ of patients are in advanced stage III and IV upon presentation $(4,5)$. The understanding of the molecular pathways of carcinogenesis or progression would be helpful in improving diagnosis, therapy and prevention of this disease.

MicroRNAs (miRNAs) are small ( 20-22 nucleotides), endogenous, noncoding RNAs, functioning as negative regulators of gene expression through antisense complimentarity to their target messenger RNAs (6). Evidence suggests that disordered expression of miRNAs contributes to the initiation and progression of human cancer $(7,8)$. A previous study conducted by Wong et al evaluated the miRNA expression patterns in human tongue squamous cell carcinoma and revealed that miR-26b, an miRNA known to have tumor-suppressive properties, was downregulated in human tongue squamous cell carcinoma tissues (9). Reduced miR-26b expression has been observed in several types of tumors, including breast, colorectal and pancreatic cancer, and it may play an important role in the regulation of carcinogenesis and tumor progression via targeting specific signaling pathways (10-15).

In the present study, we revealed that reduced miR-26b expression was correlated with advanced clinical stage, lymph node metastasis, and poor prognosis in patients with tongue squamous cell carcinoma. More importantly, we illustrated that miR-26b could regulate the malignant phenotype of human tongue squamous cell carcinoma cells by directly targeting PTGS2 (prostaglandin-endoperoxide synthase-2, encoding COX-2), a known mediator of cell proliferation and metastasis $(16,17)$. Thus, our findings provide valuable clues towards understanding the specific tumor-suppressive function and the regulatory mechanisms of miR-26b in human tongue squamous cell carcinoma. Further investigation may validate miR-26b as an effective therapeutic target in the future.

\section{Materials and methods}

Clinical samples. Tissues of tongue squamous cell carcinoma and the matched normal counterparts were obtained from surgical specimens collected immediately after resection from patients undergoing primary surgical treatment of oral 
tongue carcinoma at the Department of Stomatology, The First Affiliated Hospital of the PLA General Hospital, and Department of Stomatology, Wuhan General Hospital of Guangzhou Command. The samples were flash frozen in liquid nitrogen and stored at $-80^{\circ} \mathrm{C}$. Histology of the tissues was evaluated by the hospital pathologist. Written consent of tissue donation for research purposes was obtained from patients before tissue collection, and the protocol was approved by the Ethics Committees of The First Affiliated Hospital of the PLA General Hospital, and Wuhan General Hospital of Guangzhou Command.

Cell culture and cell transfection. Human tongue squamous cell carcinoma cell lines HSC-3, SCC-4 and Cal27, and human normal oral keratinocytes ( $\mathrm{hNOKs)} \mathrm{were} \mathrm{routinely} \mathrm{cultured} \mathrm{in}$ RPMI-1640 medium (Hyclone Laboratories, Logan, UT, USA) supplemented with $10 \%$ fetal bovine serum (Hyclone) at $37^{\circ} \mathrm{C}$ in a $5 \% \mathrm{CO}_{2}$ incubator. For transient transfection, the cells were transfected with miR-26b mimics/inhibitor and their respective negative control duplexes (Ambion, Austin, TX, USA) using Lipofectamine 2000 (Invitrogen Life Technologies, Carlsbad, CA, USA). After a 24-h transfection, the cells were collected for quantitative real-time RT-PCR (qRT-PCR) analysis or further processing.

$q R T-P C R$. The TaqMan stem-loop RT-PCR method was used to assess the expression of mature miR-26b with kits from Applied Biosystems (Foster City, CA, USA). The real-time PCR results, recorded as threshold cycle numbers $(\mathrm{Ct})$, were normalized against an internal control (U6). For relative expression levels, the $2^{-\Delta \mathrm{Ct}}$ method was used as previously described (18). Experiments were carried out in triplicate for each data point, and analysis was carried out by using Bio-Rad IQ software.

Cell cycle analysis. Cells transfected with miR-26b mimics/inhibitor were harvested $24 \mathrm{~h}$ later by trypsinization, washed with ice-cold PBS, fixed in $70 \%$ ethanol and stored at $4^{\circ} \mathrm{C}$. Following overnight incubation, cells were washed and resuspended in propidium iodide (PI) staining buffer. DNA content was evaluated by flow cytometry (XL-MCL; Coulter Epics, Miami, FL, USA).

Apoptosis analysis. Detection of apoptotic cells by flow cytometry was performed as described previously (19). Cells transfected with miR-26b mimics/inhibitor were harvested $24 \mathrm{~h}$ later and then Annexin V/PI analysis by flow cytometry (XL-MCL; Coulter Epics) was performed.

Migration and invasion analysis. Transwell chambers $(8-\mu \mathrm{m}$ pore size, Corning, Inc., Corning, NY, USA) were used in the migration and invasion analysis. For migration assays, $1 \times 10^{5}$ cells were plated in the top chamber lined with a non-coated membrane. For invasion assays, the chamber inserts were coated with $200 \mu \mathrm{g} / \mathrm{ml}$ of Matrigel and dried overnight under sterile conditions. Then, $1 \times 10^{5}$ cells were plated in the top chamber. In both assays, cells were suspended in medium without serum or growth factors, and medium supplemented with serum was used as a chemoattractant in the lower chamber. After incubation at $37^{\circ} \mathrm{C}$ for $48 \mathrm{~h}$, the top chambers were wiped with cotton
Table I. Relationship between the clinicopathological parameters and miR-26b expression in the human tongue squamous cell carcinoma cases.

\begin{tabular}{|c|c|c|c|}
\hline Variable & $\begin{array}{c}\text { No. of } \\
\text { cases }(\%)\end{array}$ & $\begin{array}{l}\text { miR-26b } \\
\text { expression }\end{array}$ & P-value \\
\hline \multicolumn{4}{|l|}{ Age (years) } \\
\hline$\geq 60$ & $17(56.7)$ & $-13.35 \pm 0.59$ & 0.739 \\
\hline$<60$ & $13(43.3)$ & $-13.03 \pm 0.74$ & \\
\hline \multicolumn{4}{|l|}{ Gender } \\
\hline Male & $19(63.3)$ & $-13.47 \pm 0.63$ & 0.459 \\
\hline Female & $11(36.7)$ & $-12.76 \pm 0.62$ & \\
\hline \multicolumn{4}{|l|}{ Tumor size } \\
\hline$\geq 4$ & $8(26.7)$ & $-12.72 \pm 0.76$ & 0.532 \\
\hline$<4$ & $22(73.3)$ & $-13.39 \pm 0.56$ & \\
\hline \multicolumn{4}{|l|}{ Differentiation } \\
\hline Well/moderately & $20(66.7)$ & $-13.50 \pm 0.60$ & 0.377 \\
\hline Poor/undifferentiated & $10(33.3)$ & $-12.63 \pm 0.67$ & \\
\hline \multicolumn{4}{|l|}{ TNM stage } \\
\hline I and II & $15(50)$ & $-12.24 \pm 0.63$ & 0.032 \\
\hline III and IV & $15(50)$ & $-14.18 \pm 0.58$ & \\
\hline \multicolumn{4}{|l|}{ Lymph node status } \\
\hline No metastasis & $16(53.3)$ & $-12.27 \pm 0.59$ & 0.026 \\
\hline Metastasis & $14(46.7)$ & $-14.28 \pm 0.62$ & \\
\hline
\end{tabular}

wool to remove the non-migrating or non-invasive cells. The invasive cells on the underside of the membrane were fixed in $100 \%$ methanol for $10 \mathrm{~min}$, air-dried, stained with $0.1 \%$ crystal violet and counted under a microscope. The mean of triplicate assays for each experimental condition was used.

Western blot analysis. Total cell lysate was prepared in 1X SDS buffer. Equal amounts of protein were analyzed by western blotting, using antibodies against COX-2, VEGF-C, cyclin D1 and $\beta$-actin (Santa Cruz Biotechnology, Santa Cruz, CA, USA).

Luciferase assay. The 3'UTR segments of PTGS2 mRNA containing the miR-26b binding sites were amplified by PCR from human genomic DNA and inserted into the pMIR-Report luciferase reporter vector (Ambion) and named pMIR-PTGS2-3'UTR. A mutant version from the site of perfect complementarity was also generated and named pMIR-mut-PTGS2-3'UTR. The recombinant reporter vectors with wild-type or mutant PTGS2 3'UTR were then cotransfected with miR-26b mimics or control into SCC-4 cells, respectively, using Lipofectamine ${ }^{\mathrm{TM}}$ 2000. The luciferase assay was performed according to the manufacturer's instructions.

Statistical analysis. The data are expressed as means \pm SEM. Differences were compared by one-way ANOVA analysis followed by the LSD t-test. Survival curves were plotted by the Kaplan-Meier's method, and the log-rank test was carried 

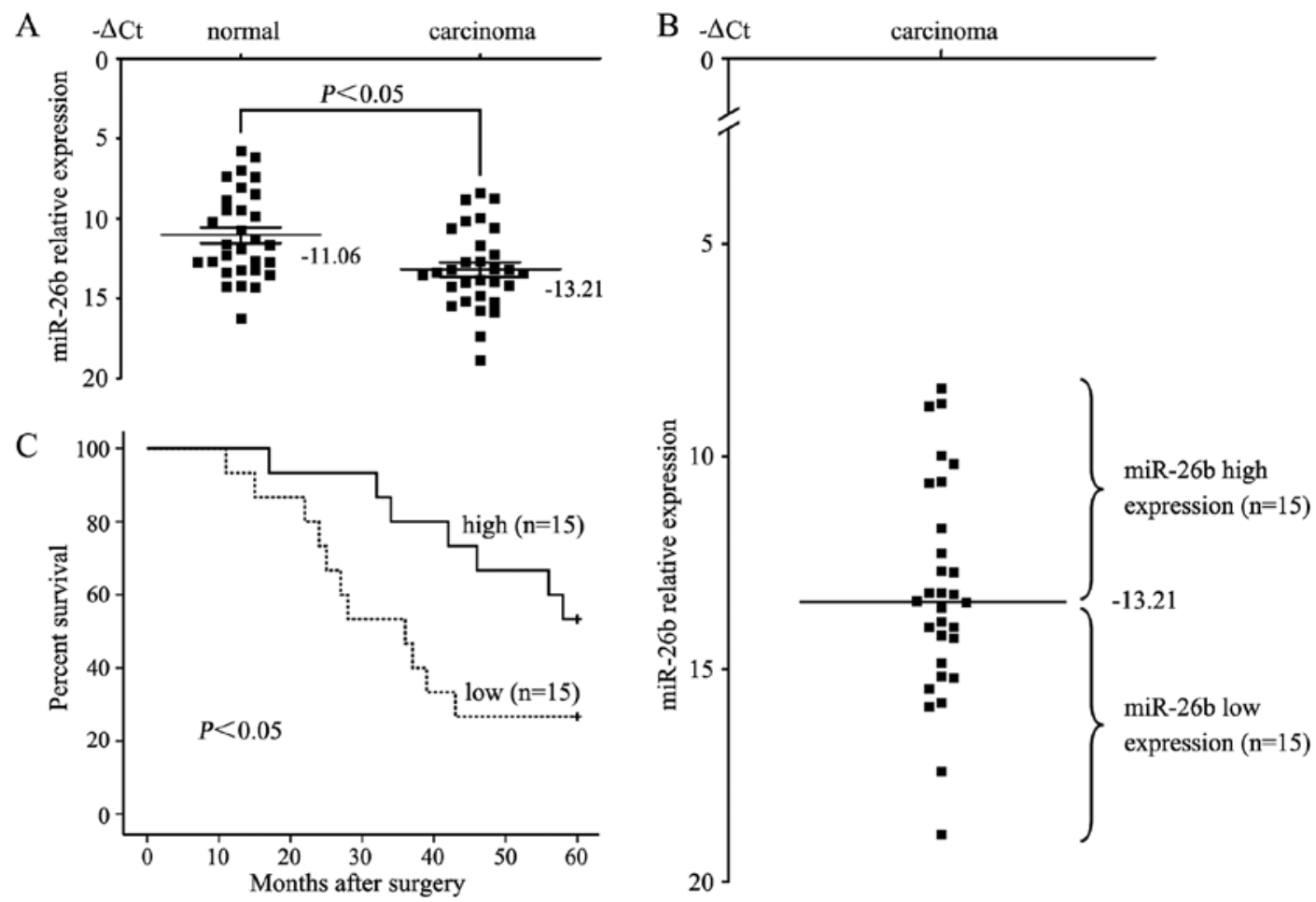

Figure 1. miR-26b expression in clinical samples. (A) miR-26b was differentially expressed between the tongue squamous cell carcinoma tissues and the corresponding adjacent non-neoplastic mucosal tissues $(n=30, P<0.05)$. (B) Samples of human tongue squamous cell carcinoma were divided into 2 groups according to the mean expression of miR-26b (mean= -13.21). Cases with levels of miR-26b below the mean were miR-26b low expressors ( $\mathrm{n}=15$ ), and those with levels of miR-26b above the mean were miR-26b high expressors $(n=15)$. (C) Kaplan-Meier survival curve and log-rank test for patients with high and low miR-26b expression $(\mathrm{P}<0.05)$.

out to compare differences in survival. All statistical analyses were performed using SPSS 19.0 software (SPSS Inc., Chicago, IL, USA). P $<0.05$ was considered to indicate a statistically significant difference.

\section{Results}

Expression of miR-26b is downregulated in human tongue squamous cell carcinoma and is associated with poor patient survival. To investigate the role of miR-26b in human tongue squamous cell carcinoma, we first compared the expression levels of miR-26b between carcinoma tissue samples and paired adjacent non-neoplastic mucosal tissues from 30 cases of tongue squamous cell carcinoma patients. Consistent with the microarray results presented by Wong et al (9), the qRT-PCR results verified that the miR-26b expression level in tongue squamous cell carcinoma tissues $(-13.21 \pm 0.46)$ was significantly lower than that in the non-neoplastic mucosal tissues $(-11.06 \pm 0.50)(\mathrm{P}<0.05, \mathrm{t}=8.355$, paired $\mathrm{t}$-test) (Fig. 1A). Correlations between the miR-26b expression level and clinicopathologic characteristics of the tongue squamous cell carcinoma cases are summarized in Table I. Statistically significant associations between miR-26b expression and clinical stage and between miR-26b expression and metastasis were observed in the present study. The median expression of miR-26b was $-14.18 \pm 0.58$ in the 15 cases with advanced stage (stage III and IV) disease, whereas the median expression was $-12.24 \pm 0.63(\mathrm{P}<0.05$, Mann-Whitney $\mathrm{U}$ test $)$ in the other 15 cases with early-stage (stages I and II) disease. In the
14 cases with lymph node metastasis, the median expression of miR-26b was $-14.28 \pm 0.62$, which was significantly lower than the median expression $(-12.24 \pm 0.63)$ in the 16 non-metastatic cases $(\mathrm{P}<0.05)$. The expression of miR-26b in the tongue squamous cell carcinoma patients did not correlate with age, gender, tumor size, or cell differentiation. Moreover, we examined whether the level of miR-26b expression was associated with survival in the patients with tongue squamous cell carcinoma. Patients were subsequently divided into low expression $(n=15)$ and high expression groups $(\mathrm{n}=15)$ based on miR-26b levels greater or less than the mean (-13.21) (Fig. 1B). Kaplan-Meier's survival analysis revealed that patients whose primary tumors displayed low expression of miR-26b had a shorter median survival time. The 5-year survival rate of patients with low miR-26 expression was $26.7 \%$, which was significantly lower than the survival rate in patients with high miR-26b expression (53.3\%, P<0.05, log-rank test, Fig. 1C).

Association between miR-26b expression and tumorigenesis of human tongue squamous cell carcinoma cells. We further detected the expression of miR-26b in hNOKs and 3 human tongue squamous cell carcinoma cell lines, HSC-3, SCC-4 and Cal27. As shown in Fig. 2A, all of the 3 carcinoma cell lines had a relatively low miR-26b expression compared to that of the hNOKs. Among the 3 carcinoma cell lines, SCC- 4 cells had a moderate expression of miR-26b. Therefore, the SCC-4 cells were chosen to evaluate the effects of miR-26b expression on the oncogenicity of human tongue squamous cell carcinoma cells. Fig. 2B shows that miR-26b expression 

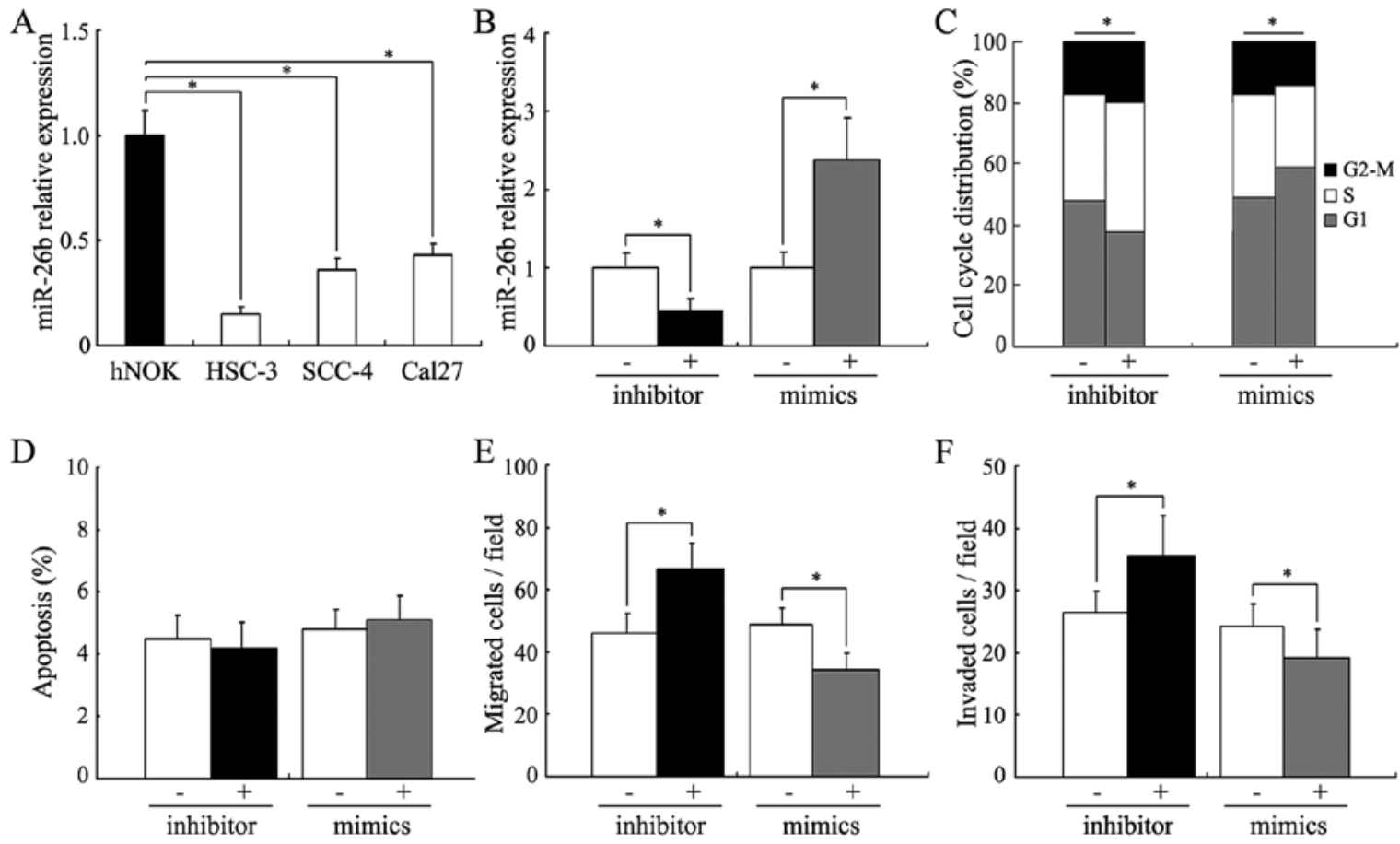

Figure 2. Effects of miR-26b expression on the tumorigenesis of human tongue squamous cell carcinoma cells. (A) miR-26b expression in human normal oral keratinocytes (hNOKs) and tongue squamous cell carcinoma cells (HSC-3, SCC-4 and Cal27). (B) miR-26b expression in the SCC-4 cells transfected with the miR-26b-specific inhibitor/mimics or the negative control. Effects of miR-26b expression on (C) proliferation, (D) apoptosis, (E) migration and (F) invasion. Data represent means \pm SEM $(n=5)$. ${ }^{*} \mathrm{P}<0.05$, vs. the negative control.

A

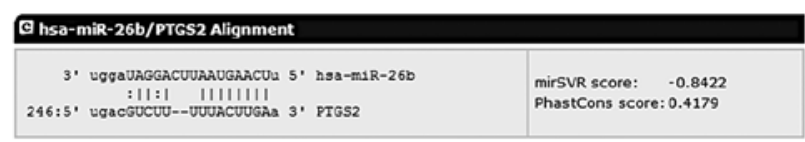

Bioinformatics prediction by miRanda

$\mathrm{C}$

\begin{tabular}{|c|c|}
\hline hsa-miR-26b & $\begin{array}{l}\text {-UGGAUAGGACUUAAUGAACUU-5' } \\
\qquad|||\|| \mid\end{array}$ \\
\hline COX-2 3'UTR & 5' -UUUGACGUCUUU--UUACUUGAA-3' \\
\hline 23 'UTR m & 5' -UUUGACGUCUUU--GCGAUUAGA-3, \\
\hline
\end{tabular}

B

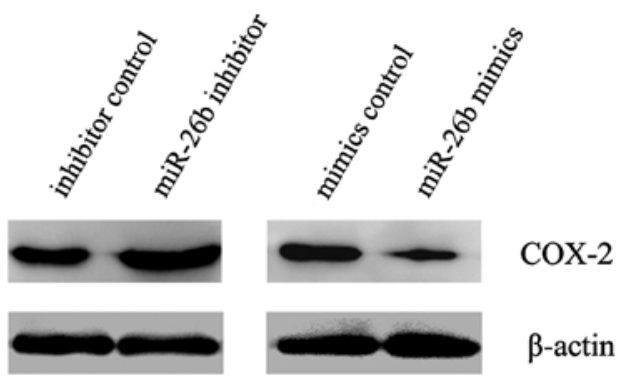

$\mathrm{D}$

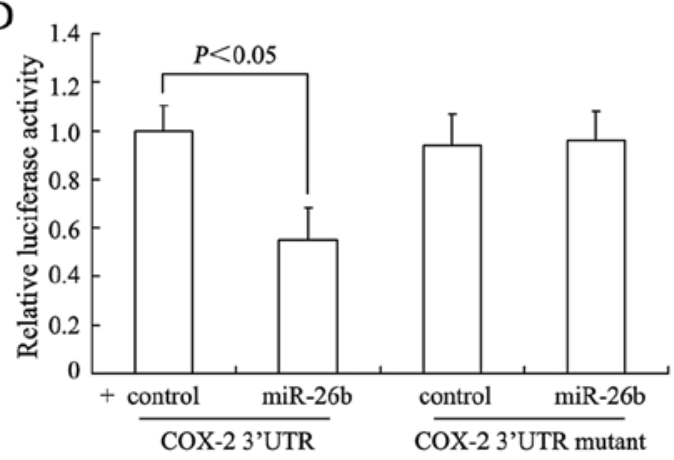

Figure 3. COX-2 is the direct functional target of miR-26b. (A) Bioinformatics prediction by miRanda. (B) The expression changes in COX-2 protein in the SCC-4 cells after miR-26b-specific inhibitor or mimic transfection. (C) Construct sequence alignment of the miR-26b seed region and the predicted miR-26b binding site in COX-2 3'UTR (wild-type), and the mutant construct obtained by site-directed mutagenesis by changing 6-base pairs of miR-26b seed-sequence (mutant). (D) Assay for luciferase activity was performed in SCC-4 cells. The values are the means from 5 independent experiments \pm SEM.

was strongly reduced or increased in the SCC-4 cells after transfection of the miR-26b-specific inhibitor or mimics. By flow cytometry, a significant accumulation of cells in the G1 phase was observed in the miR-26b-upregulated SCC-4 cells, while inhibition of miR-26b expression led to increased cell proliferation (Fig. 2C, $\mathrm{P}<0.05$ ). No significant influence on apoptosis was observed in the SCC-4 cells after treatment with the miR-26b specific inhibitor or mimics (Fig. 2D). We further 
A

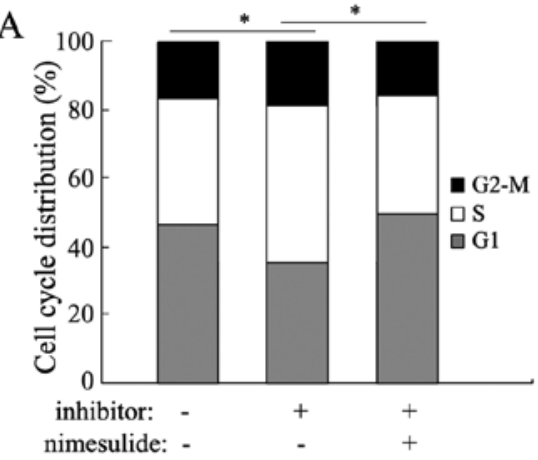

C

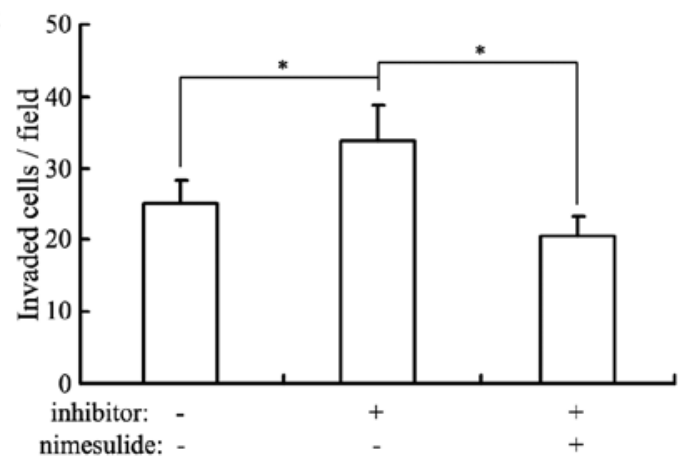

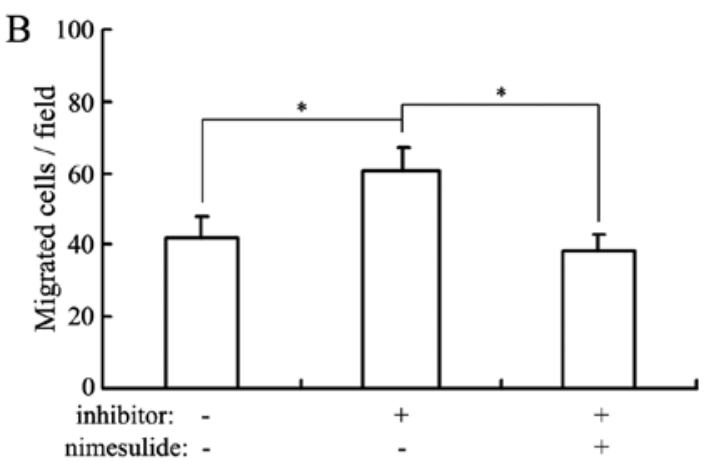

D

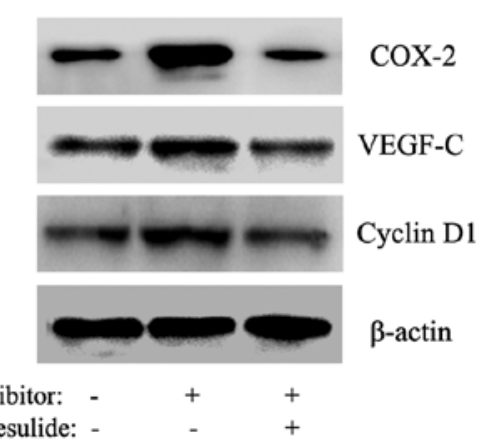

Figure 4. Influence of nimesulide on proliferation, migration and invasion in miR-26b-downregulated SCC-4 cells. After a 24-h transfection of the miR-26b-specific inhibitor, SCC-4 cells were collected by centrifugation and then exposed to nimesulide (100 $\mu$ mol/1) for another $6 \mathrm{~h}$. (A) Cell cycle analysis by flow cytometry. (B and C) Results of the migration and invasion assays. (D) Western blot analysis of COX-2, VEGF-C, cyclin D1 and $\beta$-actin in the SCC-4 cells. Data represent means $\pm \operatorname{SEM}(n=5)$. $\mathrm{P}<0.05$.

performed Transwell assays to determine whether altered miR-26b expression could influence the metastatic phenotype of the SCC-4 cells. As shown in Fig. 2E and F, miR-26b inhibition significantly increased the ability of the SCC-4 cells to migrate and invade, while miR-26b upregulation suppressed the migration and invasion $(\mathrm{P}<0.05)$.

COX-2 is the direct functional target of miR-26b. Using bioinformatics analysis, such as miRanda and TargetScan, we found that miR-26b contained specific binding sequences for the 3'UTR region of the COX-2 gene (PTGS2) (Fig. 3A). In agreement with the computer prediction, $\mathrm{COX}-2$ protein levels were significantly suppressed in the miR-26b mimic group whereas these levels were increased in the miR-26b inhibitor group (Fig. 3B). In order to further validate the relationship between miR-26b and COX-2, a dual luciferase reporter assay was performed in the SCC- 4 cells. The sequences of the 3'UTR of wild-type and mutated COX-2 are shown in Fig. 3C. No reduction in luciferase activity was observed in the SCC-4 cells transfected with miR-26b mimics and mutated COX-2, but an $\sim 45 \%$ reduction in luciferase activity was observed in wild-type COX-2 (P<0.05, Fig. 3D).

A COX-2-dependent mechanism is involved in the regulation of oncogenesis induced by $m i R-26 b$. We further investigated the influence of nimesulide, a COX-2-specific inhibitor, on the proliferation, migration and invasion of SCC-4 cells (20). As shown in Fig. 4A-C, nimesulide abolished the promoting effects of miR-26b inhibition on the proliferation, migration and invasion in SCC-4 cells, suggested the critical role of COX-2 in miR-26b-regulated oncogenesis $(\mathrm{P}<0.05)$. Previous studies revealed that COX-2 could promote the proliferation and metastasis of human tongue squamous cell carcinoma cells through the VEGF-C pathway (21-25). In the present study, we investigated the expression changes of VEGF-C in SCC- 4 cells by western blot analysis. As shown in Fig. 4D, the protein level of VEGF-C was significantly increased in the miR-26b-silenced SCC-4 cells, however, this was reversed by treatment of nimesulide. We also investigated the expression changes in cyclin D1, a key cell cycle-regulatory protein. Western blot analysis results indicated that cyclin D1 was also significantly upregulated in the miR-26b-silenced SCC-4 cells and this upregulation was reversed by nimesulide.

\section{Discussion}

Dysregulation of miRNAs is common in various cancers. Dysregulated miRNAs play a role in carcinogenesis or tumor progression by altering the normal gene expression patterns. miR-26b has been found to be downregulated in several types of human tumors and has been suggested to be a tumor-suppressor gene (10-15). In the present study, we confirmed the decrease in miR-26b expression in human tongue squamous cell carcinoma and defined the clinical importance of miR-26b in predicting lymph node metastasis and survival. Furthermore, we identified that COX-2 is the functional target of miR-26b in human tongue squamous cell carcinoma cells.

miR-26b (hsa) is classified as a member of the miR-26 family (miR-26a/b) and has been reported as a critical regulator in carcinogenesis and tumor progression by acting as a tumor-suppressor gene in various cancers (10-15). 
miR-26b was first revealed to be downregulated in human breast cancer tissues and to mediate the proliferation and apoptosis of human breast cancer cells through targeting SLC7A11, PTGS2 (encoding COX-2) and CDK8 $(10,26,27)$. Subsequently, miR-26b was found to be downregulated in human colorectal, pancreatic and parathyroid cancer, glioma and hepatocellular carcinoma (11-15), further indicating the tumor suppressive property of this miRNA. Wong et al and Hsu et al (28) consistently reported that miR-26b expression was decreased in human head and neck cancer tissues compared with that in paired normal tissues. In human tongue squamous cell carcinoma, Wong et al revealed that miR-26b had a $\sim 4$-fold reduction in expression level in laser capture microdissection-procured carcinoma cells compared with the matched normal cells (9). In the present study, we confirmed the reduced expression of miR-26b in 30 cases of tongue squamous cell carcinoma patients and revealed that its expression was associated with clinical stage, lymph node metastasis, and survival prognosis.

The PTGS2 gene encodes the COX-2 enzyme, which catalyzes the conversion of arachidonic acid to prostaglandins and other eicosanoids. COX-2 expression is undetectable in most normal tissues but is induced in response to hypoxia, inflammatory cytokines, tumor promoters, growth factors and other stressors (17). Mounting evidence has revealed that COX-2 expression is overexpressed in a variety of human tumors, including human tongue squamous cell carcinoma (29-31). COX-2 overexpression may contribute to carcinogenesis by modulating metabolism, proliferation, apoptosis, metastasis, angiogenesis and immune surveillance. Several clinical studies have established the potent anticancer activity of COX-2 inhibition by using COX-2 specific inhibitors (such as celecoxib) $(32,33)$. Targeting COX-2 with specific miRNAs may be another reasonable approach to inhibit COX-2 activity. At present, many miRNA-based cancer therapeutics is either in the preclinical or clinical trial phase. In the present study, we observed that ectopic expression of miR-26b could inhibit the proliferation and metastasis of human tongue squamous cell carcinoma cells and revealed that miR-26b could decrease the protein level of COX-2 by directly binding to its 3'UTR. Considering the reduced expression of miR-26b and the critical role of COX-2 expression in carcinogenesis, we suggest that the replacement therapy of miR-26b, for example lentiviral-mediated delivery of mimic miR-26b, may be a promising therapeutic approach for human tongue squamous cell carcinoma.

Taken together, we revealed that reduced miR-26b expression is correlated with advanced clinical stage, lymph node metastasis, and poor prognosis in patients with tongue squamous cell carcinoma. In addition, we provide evidence that COX-2 is the direct functional target of miR-26b. These results indicate that miR-26b may serve as a tumor-suppressor gene involved in human tongue squamous cell carcinoma.

\section{References}

1. Albuquerque R, López-López J, Marí-Roig A, Jané-Salas E Roselló-Llabrés $\mathrm{X}$ and Santos JR: Oral tongue squamous cell carcinoma (OTSCC): alcohol and tobacco consumption versus non-consumption. A study in a Portuguese population. Braz Dent J 22: 517-521, 2011.
2. Marocchio LS, Lima J, Sperandio FF, Corrêa L and de Sousa SO: Oral squamous cell carcinoma: an analysis of 1,564 cases showing advances in early detection. J Oral Sci 52: 267-273, 2010.

3. Pettus JR, Johnson JJ, Shi Z, Davis JW, Koblinski J, et al: Multiple kallikrein (KLK 5, 7,8, and 10) expression in squamous cell carcinoma of the oral cavity. Histol Histopathol 24: 197-207, 2009.

4. Yuen PW, Lam KY, Chan AC, Wei WI and Lam LK: Clinicopathological analysis of local spread of carcinoma of the tongue. Am J Surg 175: 242-244, 1998.

5. Po Wing Yuen A, Lam KY, et al: Prognostic factors of clinically stage I and II oral tongue carcinoma - a comparative study of stage, thickness, shape, grow th pattern, invasive front malignancy grading, Martinez-Gimeno score, and pathologic features. Head Neck 24: 513-520, 2002.

6. Bartel DP: MicroRNAs: target recognition and regulatory functions. Cell 136: 215-233, 2009.

7. Kasinski AL and Slack FJ: Epigenetics and genetics. MicroRNAs en route to the clinic: progress in validating and targeting microRNAs for cancer therapy. Nat Rev Cancer 11: 849-864, 2011.

8. Iorio MV and Croce CM: MicroRNA dysregulation in cancer: diagnostics, monitoring and therapeutics. A comprehensive review. EMBO Mol Med 4: 143-159, 2012.

9. Wong TS, Liu XB, Wong BY, Ng RW, Yuen AP and Wei WI: Mature miR-184 as potential oncogenic microRNA of squamouscell carcinoma of tongue. Clin Cancer Res 14: 2588-2592, 2008.

10. Liu XX, Li XJ,Zhang B, et al: MicroRNA-26b is underexpressed in human breast cancer and induces cell apoptosis by targeting SLC7A11. FEBS Lett 585: 1363-1367, 2011.

11. Zhang C, Tong J and Huang G: Nicotinamide phosphoribosyl transferase (Nampt) is a target of microRNA-26b in colorectal cancer cells. PLoS One 8: e69963, 2013.

12. Schultz NA, Dehlendorff C, Jensen BV, et al: MicroRNA biomarkers in whole blood for detection of pancreatic cancer. JAMA 311: 392-404, 2014.

13. Rahbari R, Holloway AK, He M, Khanafshar E, Clark OH and Kebebew E: Identification of differentially expressed microRNA in parathyroid tumors. Ann Surg Oncol 18: 1158-1165, 2011.

14. Wu N, Zhao X, Liu M, et al: Role of microRNA-26b in glioma development and its mediated regulation on EphA2. PLoS One 6: e16264, 2011.

15. Ji J, Shi J, Budhu A, Yu Z, et al: MicroRNA expression, survival, and response to interferon in liver cancer. N Engl J Med 361: $1437-1447,2009$.

16. Speed N and Blair IA: Cyclooxygenase- and lipoxygenasemediated DNA damage. Cancer Metastasis Rev 30: 437-447, 2011.

17. Khan Z, Khan N, Tiwari RP, et al: Biology of Cox-2: an application in cancer therapeutics. Curr Drug Targets 12: 1082-1093, 2011.

18. Livak KJ and Schmittgen TD: Analysis of relative gene expression data using real-time quantitative PCR and the 2(-Delta Delta C(T)) method. Methods 25: 402-408, 2001.

19. Zhang YF, Zhang AR, Zhang BC, Rao ZG, et al: MiR-26a regulates cell cycle and anoikis of human esophageal adenocarcinoma cells through Rb1-E2F1 signaling pathway. Mol Biol Rep 40: 1711-1720, 2013.

20. Suleyman H, Cadirci E, Albayrak A and Halici Z: Nimesulide is a selective COX-2 inhibitory, atypical non-steroidal anti-inflammatory drug. Curr Med Chem 15: 278-283, 2008.

21. Morita Y, Morita N, Hata K, et al: Cyclooxygenase-2 expression is associated with vascular endothelial growth factor-c and lymph node metastasis in human oral tongue cancer. Oral Surg Oral Med Oral Pathol Oral Radiol 117: 502-510, 2014.

22. Kono M, Watanabe M, Abukawa H, Hasegawa O, Satomi T and Chikazu D: Cyclo-oxygenase-2 expression is associated with vascular endothelial growth factor $\mathrm{C}$ expression and lymph node metastasis in oral squamous cell carcinoma. J Oral Maxillofac Surg 71: 1694-1702, 2013.

23. Morita Y, Hata K, Nakanishi M, Nishisho T, Yura Y and Yoneda T: Cyclooxygenase-2 promotes tumor lymphangiogenesis and lymph node metastasis in oral squamous cell carcinoma. Int J Oncol 41: 885-892, 2012.

24. Wang YH, Wu MW, Yang AK, et al: COX-2 gene increases tongue cancer cell proliferation and invasion through VEGF-C pathway. Med Oncol 28: S360-S366, 2011. 
25. Kyzas PA, Stefanou D and Agnantis NJ: COX-2 expression correlates with VEGF-C and lymph node metastases in patients with head and neck squamous cell carcinoma. Mod Pathol 18 153-160, 2005.

26. Li J, Kong X, Zhang J, Luo Q, Li X and Fang L: MiRNA-26b inhibits proliferation by targeting PTGS2 in breast cancer. Cancer Cell Int 13: 7, 2013.

27. Li J, Li X, Kong X, Luo Q, Zhang J and Fang L: MiRNA-26b inhibits cellular proliferation by targeting CDK8 in breast cancer. Int J Clin Exp Med 7: 558-565, 2014.

28. Hsu CM, Lin PM, Wang YM, Chen ZJ, Lin SF and Yang MY: Circulating miRNA is a novel marker for head and neck squamous cell carcinoma. Tumour Biol 33: 1933-1942, 2012.
29. Rizzo MT: Cyclooxygenase-2 in oncogenesis. Clin Chim Acta 412: 671-687, 2011.

30. Ghosh N, Chaki R, Mandal V and Mandal SC: COX-2 as a target for cancer chemotherapy. Pharmacol Rep 62: 233-244, 2010.

31. Lin DT, Subbaramaiah K, Shah JP, Dannenberg AJ and Boyle JO: Cyclooxygenase-2: a novel molecular target for the prevention and treatment of head and neck cancer. Head Neck 24: 792-799, 2002.

32. Ghosh N, Chaki R, Mandal V and Mandal SC: COX-2 as a target for cancer chemotherapy. Pharmacol Rep 62: 233-244, 2010.

33. Kraus S, Naumov I and Arber N: COX-2 active agents in the chemoprevention of colorectal cancer. Recent Results Cancer Res 191: 95-103, 2013 